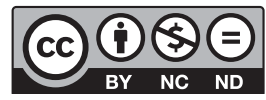

Estudos Teológicos foi licenciado com uma Licença Creative Commons Atribuição - NãoComercial - SemDerivados 3.0 Não Adaptada

http://dx.doi.org/10.22351/et.v59i1.3579

\title{
CrucificaÇão e abuso SeXual ${ }^{1}$
}

\author{
Crucifixion and sexual abuse
}

\section{David Tombs ${ }^{2}$}

Resumo: Este artigo recorre à hermenêutica da libertação latino-americana para ler as narrativas dos evangelhos sobre a crucificação à luz dos relatos de tortura na América Latina. As práticas de tortura empregadas por regimes autoritários da América Latina nos anos 1970 e 1980 mostram como a tortura foi usada para o terror de Estado. Relatos sobre essa época também confirmam a frequência da violência sexual em práticas de tortura. Aplicando essa perspectiva a uma leitura das narrativas dos evangelhos, o artigo sustenta que os romanos também usaram a crucificação como terror de Estado. As crucificações romanas eram punições públicas para intimidar e controlar escravos e povos sujeitados. Além disso, para reforçar a mensagem de terror, as crucificações incluíam humilhação sexual para degradar e rebaixar suas vítimas. O artigo sustenta que o desnudamento e a exibição de Jesus nu registrados nos evangelhos constituíram uma forma de humilhação sexual e deveriam ser chamados de abuso sexual. Ele também pergunta se outros abusos sexuais poderiam ter ocorrido no pretório. Conclui que a possibilidade de outros abusos é uma questão importante a ser considerada, mesmo que não possa ser respondida com certeza.

Palavras-chave: Jesus. Crucificação. Abuso sexual. Tortura. Terror de Estado.

Abstract: This article resorts to the hermeneutics of Latin American liberation to read the narratives of the Gospels about crucifixion in the light of reports of torture in Latin America. The torture practices employed by authoritarian regimes in Latin America in the 1970s and 1980s show how torture was used for state terror. Reports from this period also confirm the frequency of sexual violence in torture practices. Applying this perspective to a reading of Gospel narratives, the article maintains that the Romans also used crucifixion as state terror. The Roman crucifixions were public punishments for intimidating and controlling slaves and subjected peoples. In addition, to reinforce the message of terror, the crucifixions included sexual humiliation to degrade and demean their victims. The article maintains that the stripping and display of the naked Jesus

1 O artigo foi recebido em 06 de fevereiro de 2019 e aprovado em 23 de abril de 2019 com base nas avaliações dos pareceristas ad hoc.

2 Doutor em Teologia. Professor de Teologia e Assuntos Públicos na Universidade de Otago em Dunedin, Nova Zelândia. Contato: david.tombs@otago.ac.nz 
recorded in the Gospels constituted a form of sexual humiliation and should be called sexual abuse. It also asks if other sexual abuse could have occurred in the praetorium. It concludes that the possibility of further abuse is an important question to consider, even if it cannot be answered with certainty.

Keywords: Jesus. Crucifixion. Sexual abuse. Torture. State terror.

\section{Introdução}

A Bíblia sempre é lida tendo-se um contexto em mente. ${ }^{3}$ Fazem-se suposições sobre o contexto social original do texto e elas são, na maioria das vezes, derivadas conscientemente ou de outra forma - do contexto social presente do leitor ou leitora ou do crítico ou crítica. Em décadas recentes, o valor positivo do reconhecimento dessas conexões tem sido defendido por teologias contextuais na América Latina e em outros lugares. Embora alguns críticos e críticas tenham alertado, com razão, contra a tentação de equiparar superficialmente contextos sociais contemporâneos e o mundo bíblico, as pessoas comprometidas com uma abordagem contextual têm sustentado que, quando usado apropriadamente, um engajamento sério com contextos sociais contemporâneos pode oferecer percepções do contexto bíblico e, consequentemente, de aspectos negligenciados do texto bíblico. ${ }^{4}$

Uma área em que, creio eu, semelhanças compartilhadas entre contextos do passado e do presente podem ser investigadas com o maior proveito é a arena política do terror de Estado e do uso de tortura para essa finalidade. Os regimes militares da América Latina usaram o terror de Estado nos anos 1970 e 1980 para criar medo e promover o fatalismo em toda a sociedade. Uma compreensão disso proporciona um contexto para reconhecer as crucificações romanas como instrumentos de terror de Estado. Além disso, as práticas de tortura na América Latina implicaram tentativas deliberadas de envergonhar as vítimas e minar seu senso de dignidade. Tortura física e agressões foram muitas vezes combinadas com humilhação psicológica na tentativa

3 Este artigo é uma versão resumida de um texto publicado pela primeira vez em inglês: TOMBS, David. Crucifixion, State Terror, and Sexual Abuse. Union Seminary Quarterly Review, v. 53, p. 89-109, 1999. $\mathrm{O}$ argumento central foi apresentado pela primeira vez sob o título "Biblical Interpretation in Latin America: Crucifixion, State Terror, and Sexual Abuse” na Seção de Hermenêutica Bíblica da Conferência Internacional da Sociedade de Literatura Bíblica, em 20 de julho de 1998, em Cracóvia, Polônia. Esta versão mais breve é oferecida como parte do projeto da Universidade de Otago sobre o reconhecimento de Jesus como vítima de abuso sexual, intitulado “Quando foi que te vimos nu?”. Uma versão mais longa, incluindo uma reflexão de Fernando Segovia, está disponível em espanhol: TOMBS, David. Crucifixión, terrorismo de Estado y abuso sexual: texto y contexto. Dunedin: Centro de Teología y Asuntos Públicos, Universidad de Otago, 2018. Sobre as reações de sobreviventes ao argumento central, cf. FIGUEROA ALVEAR, Rocío; TOMBS, David. Reconociendo a Jesús como víctima de abuso sexual: respuestas de sobrevivientes del Sodalicio en el Perú. Dunedin: Centro de Teología y Asuntos Públicos, Universidad de Otago, 2019. - Tradução do original inglês por Luís Marcos Sander.

4 Um dos desenvolvimentos mais sofisticados e abrangentes de uma hermenêutica contextual é BOFF, Clodovis. Teologia e prática: teologia do político e suas mediações. Petrópolis: Vozes, 1978. A abordagem de Boff reconhece tanto semelhanças como diferenças entre o contexto latino-americano atual e o mundo da Bíblia. 
de pôr fim à vontade da vítima de resistir ou até mesmo de viver. Agressões sexuais e humilhação sexual são uma forma particularmente eficaz de fazer isso e constituem um lugar-comum em práticas de tortura no passado e no presente.

Este artigo sustenta que práticas de tortura podem proporcionar uma compreensão mais profunda da crucificação romana como forma de terror de Estado que incluía o abuso sexual. A análise proposta abaixo recorre a relatos da América Latina, mas uma leitura semelhante poderia ser oferecida dando-se atenção à tortura em muitos outros contextos, incluindo a tortura e o abuso de prisioneiros em Abu Ghraib. ${ }^{5}$

Levantar a questão do abuso sexual em relação a Jesus poderia parecer, inicialmente, algo inapropriado. Entretanto, os relatos dos evangelhos indicam um nível surpreendente de humilhação sexual pública no tratamento dispensado a Jesus, e até mesmo isso talvez não revele todo o horror da tortura sofrida por Jesus antes de sua morte. Embora isso possa parecer uma sugestão perturbadora à primeira vista, em uma esfera teológica, um Deus que se identificou com as vítimas de abuso sexual pode ser reconhecido como um desafio positivo para a compreensão e resposta cristã contemporânea. Em uma esfera pastoral, ela poderia ajudar a sensibilizar as pessoas para a experiência daquelas que sofreram abuso sexual e, em alguns casos, poderia até se tornar um elemento de cura para as próprias vítimas.

\section{Crucificação e terror de Estado}

Golpes militares ocorridos nas décadas de 1960 e 1970 instalaram regimes militares no Brasil (1964-1985) e em todo o Cone Sul da América Latina (Chile, 1973-1989; Uruguai, 1973-1985; e Argentina, 1976-1983). Durante esses anos, abusos dos direitos humanos sancionados pelo Estado, incluindo tortura, assassinatos e desaparecimentos, eram lugar-comum. De igual maneira, nos anos 1980, os governos autoritários da Guatemala e de El Salvador estiveram envolvidos em algumas das mais brutais campanhas de repressão que a região conheceu. A transição para a democracia no Brasil e nos países do Cone Sul e os tratados de paz em El Salvador (1992) e na Guatemala (1995) motivaram investigações oficiais de abusos dos direitos humanos durante a repressão. Os relatórios publicados sobre esses países oferecem uma documentação detalhada e constituem uma leitura horrível sobre os anos de terror suportados pelas populações civis. ${ }^{6}$

\footnotetext{
5 Sobre o terror de Estado e abusos sexuais ocorridos na tortura na América Latina nos anos 1970 e 1980, cf. TOMBS, 2018. Sobre a leitura da crucificação à luz da tortura ocorrida em Abu Ghraib, cf. TOMBS, David. Prisoner Abuse: From Abu Ghraib to the Passion of the Christ. In: HOGAN, Linda; LEHRKE, Dylan (ed.). Religions and the Politics of Peace and Conflict. Princeton, NJ: Princeton Theological Monograph Series, 2009. p. 179-205.

6 Eles incluem os seguintes: ARCHDIOCESE OF SÃO PAULO. Torture in Brazil: A Report by the Archdiocese of São Paulo. New York: Vintage, 1986; NATIONAL COMMISSION ON DISAPPEARED PEOPLE. Nunca Más: A Report by Argentina's National Commission on Disappeared People. Boston and London: Faber and Faber, 1986; NATIONAL COMMISSION ON TRUTH AND RECONCILIATION. Report of the Chilean National Commission on Truth and Reconciliation. Notre Dame, IN: Centre for
} 
Qualquer compreensão da dinâmica política e social dos países durante essa época precisa abordar o uso disseminado do terror de Estado para apoiar e impor o poder ilegítimo dos regimes militares. O terror foi um meio eficaz na imposição do autoritarismo brutal por meio de uma cultura do medo. ${ }^{7} \mathrm{O}$ medo "persuade" as pessoas de que é melhor suportar injustiças de modo fatalista do que resistir a elas. A prisão e tortura de "pessoas suspeitas" pela polícia e pelos militares na América Latina não podem ser explicadas adequadamente em termos da ameaça que essas pessoas poderiam ter representado ou pela necessidade de extrair informações delas. Deveriam, isto sim, ser entendidas como ações que pretendiam paralisar a disposição de uma sociedade à resistência. Além de visar às próprias vítimas, os desaparecimentos, as torturas e execuções tinham a intenção de aterrorizar um público.

De modo semelhante, a crucificação romana era mais do que a punição de um indivíduo. No mundo da Antiguidade, as crucificações eram instrumentos dentro de políticas de terror de Estado dirigidos a uma população mais ampla. ${ }^{8}$ Como atos de terror contra pessoas potencialmente rebeldes, os romanos usaram as crucificações principalmente contra escravos e outros povos sujeitados que poderiam contestar a autoridade romana. ${ }^{9}$ Uma das mais claras ilustrações do uso da crucificação para inspirar terror é dada pela descrição de Josefo a respeito do tratamento de quem tentou fugir de Jerusalém durante o cerco promovido por Tito em 70 d.C.:

A necessidade e o temor do suplício os [sc. os judeus] obrigavam a se defender quando eram descobertos e atacados; e como não podiam esperar misericórdia, depois de se terem defendido, não a pediam também, e eram assim crucificados à vista dos que estavam na cidade. Tito achava que havia naquilo muita crueldade, pois não se passava um dia sem que não se apanhassem pelo menos uns 500 e, às vezes, mais; ele não via, porém, possibilidade de fazer voltar, àqueles que haviam sido aprisionados; [...] ele esperava que a vista de um espetáculo tão terrível poderia impressionar os judeus da cidade, pelo temor de serem tratados do mesmo modo, pois o ódio e a raiva de que os soldados romanos

Civil and Human Rights, Notre Dame Law School, 1993; TRUTH COMMISSION FOR EL SALVADOR. From Madness to Hope: The Twelve Years War in El Salvador: Report of the Truth Commission, 19921993. New York: United Nations, 1993.

7 Cf. a coletânea de ensaios que exploram essa questão a partir de diferentes disciplinas: CORRADI, Juan E. et al. (ed.). Fear at the Edge: State Terror and Resistance in Latin America. Berkeley; Los Angeles, CA: University of California Press, 1992. Sobre o uso de tortura para a promoção do terror, cf. SCARRY, Elaine. The Body in Pain: The Making and Unmaking of the World. Oxford: Oxford University Press, 1987.

8 Uma breve história da crucificação se encontra na clássica obra de Hengel: HENGEL, Martin. Crucifixion in the Ancient World and the Folly of the Cross. Philadelphia: Fortresss; London: SCM, 1977 [o original em alemão é de 1976].

9 A crucificação raramente era usada contra cidadãos romanos, e mesmo essas ocasiões infrequentes se destinavam a punir integrantes das classes baixas e não da aristocracia. Sobre o uso da crucificação pelos romanos cf. HENGEL, 1977. Exposições mais recentes são as seguintes: BROWN, Raymond E. Death of the Messiah. New York: Doubleday, 1994. p. 945-952 e bibliografia exaustiva às p. 885-887; MOORE, Stephen D. God's Gym: Divine Male Bodies of the Bible. New York: Routledge, 1996; e SLOYAN, Gerard S. The Crucifixion of Jesus: History, Myth, Faith. Minneapolis: Fortress, 1995. 
estavam possuídos, faziam sofrer àqueles míseros, antes de morrer, tudo o que se pode esperar da insolência de soldados. Não eram suficientes as cruzes, e havia já falta de lugar para tantos instrumentos de suplício (War V. 446-52) ${ }^{10}$.

A eficácia e segurança das tropas romanas na Palestina se baseavam, em última análise, nas legiões que estavam na Síria e - se necessário - em outras partes do Império. A força relativamente pequena na Palestina tinha condições de manter a ordem porque tinha o apoio da garantia de represálias severas se irrompesse uma rebelião grave. A combinação de presença moderada e ameaça maciça geralmente era suficiente para preservar a chamada "paz" da pax Romana.

As crucificações em massa com as quais os romanos reagiam a incidentes de grande porte transmitiam a mensagem de retaliação temível com uma clareza aterradora. Josefo descreve como, no ano 4 d.C., Varo (governador da Síria) reagiu ao levante causado pelo governo inepto de Arquelau, filho de Herodes, com a crucificação de dois mil "cabeças" dos distúrbios (War II. 69-79 [75]). A revolta por ocasião do censo quando Quirino era governador da Síria (6-7 d.C.) e Pocônio, procurador da Judeia (6-9 d.C.) também se deparou com amplas represálias (War II. 117-18, 167; Ant. 17.354-55, 18.1-10, 26-27). Josefo também registra que, quando Cumano (procurador da Judeia de 48 a 52 d.C.) fez uma série de prisioneiros envolvidos em uma disputa, Quadrado (governador da Síria) ordenou que todos fossem crucificados (War II. 241). De maneira semelhante, quando Félix (procurador da Judeia de 52 a 60 d.C.) se pôs a eliminar o banditismo do país, o número dos crucificados "era grande demais para ser contado" (War II. 253). Josefo também registra como, no crescendo que levou à revolta de 66 d.C., Floro (procurador de 64 a 66 d.C.) invadiu o tesouro do templo e depois - por causa dos distúrbios subsequentes - flagelou e crucificou homens, mulheres e crianças até que o número de mortos chegou a 3.600 ( War II. 305-08).

As crucificações individuais deveriam ser entendidas dentro desse contexto político. Mesmo que uma só vítima fosse crucificada, a execução era mais significativa do que a punição de uma vítima individual. A crucificação era uma forma importante pela qual as consequências horrendas da rebelião podiam ser tornadas visíveis diante do público. As crucificações individuais serviam para lembrar as pessoas das crucificações em massa e outras retaliações que os romanos estavam mais do que dispostos a usar se seu poder fosse contestado.

Há poucas descrições detalhadas de como a crucificação ocorria - os evangelhos fornecem a descrição mais completa da literatura da Antiguidade -, mas o quadro que surge se encaixa muito bem no perfil de tortura pública de Estado. ${ }^{11}$ A vítima era amarrada ou pregada a uma cruz de madeira para maximizar sua humilhação pública: um

${ }^{10}$ No original foi usada a seguinte versão em inglês: JOSEPHUS. The Jewish War. [1959]. Trad. G. A. Williamson. Ed. rev. Harmondsworth: Penguin Books, 1970. (Citação em português extraída de JOSEFO, Flávio. História dos hebreus: De Abraão à queda de Jerusalém. Trad. Vicente Pedroso. Disponível em: $<$ https://rl.art.br/arquivos/6131770.pdf $>$ ).

11 A análise de como a crucificação era usada no mundo da Antiguidade é complicada pela relação estreita existente entre crucificação, empalação e pendura de corpos (o que poderia ser feito antes ou depois da 
contraste entre a vergonha da vítima e o poderio do Império. Os romanos exibiam a vítima na beira de uma estrada ou em um lugar público semelhante. A crucificação era uma provação demorada, que podia durar muitos dias, uma agressão prolongada à dignidade do espírito humano bem como ao corpo físico. ${ }^{12} \mathrm{~A}$ vergonha para os judeus era intensificada ainda pela crença de que "quem for pendurado no madeiro é maldito" (Dt 21.23), uma maldição a que Paulo se refere em relação à crucificação de Jesus em Gl 3.13.

\section{Crucificação e abuso sexual}

Testemunhos de tortura do Brasil, da Argentina, do Chile, da América Central e de outros lugares relatam consistentemente o desnudamento e abuso sexual como parte da tortura. ${ }^{13}$ No Brasil, a tortura com choques elétricos invariavelmente incluía choques nos órgãos genitais. ${ }^{14} \mathrm{O}$ mesmo foco nos órgãos genitais se mostrou na Argentina. $\mathrm{O}$ instrumento preferencial para infligir choques elétricos na Argentina, $l a$ picana (um pequeno bastão eletrificado), é em si mesmo altamente sugestivo do elemento sexual nessa tortura. ${ }^{15}$ Seu uso no estupro e abuso sexual de mulheres foi bem documentado e ao menos duas vítimas argentinas do sexo masculino também testemunham como esse abuso acabava levando ao estupro anal. ${ }^{16}$

Para uma leitura da crucificação, dois elementos dessas práticas de tortura merecem atenção especial. Em primeiro lugar, a agressão e humilhação sexual eram práticas-padrão nas práticas de tortura de Estado, e o abuso sexual era padrão, e não

morte). Gálatas 3.13; Atos 5.30; 10.39 mostram que os autores do Novo Testamento podem transitar facilmente entre a crucificação e a pendura em uma árvore.

12 É provável que, durante a crucificação, todo o controle sobre muitas funções corporais fosse perdido. O seguinte relato de tortura com choque elétrico na Argentina feito por Nélson Eduardo Dean sugere quão humilhantes devem ter sido as consequências disso: "Durante a aplicação da eletricidade, a gente perdia todo o controle sobre os próprios sentidos, e essa tortura fazia com que se vomitasse permanentemente, se defecasse constantemente etc.” (NATIONAL COMMISSION ON DISAPPEARED PEOPLE, 1986, p. 39).

13 Exemplos adicionais se encontram em TOMBS, 2018.

14 " [...] foi conduzido às dependências do DOI-CODI, onde foi torturado nu, após tomar um banho pendurado no pau-de-arara, onde recebeu choques elétricos, através de um magneto, em seus órgãos genitais e por todo o corpo" (José Milton Ferreira de Almeida) (ARCHDIOCESE OF SÃO PAULO, 1986, p. 17; versão em português extraída de <http://www.janduarte.com.br/textos/brasil/brasil_nunca_mais.pdf $>$ ).

15 Sobre o uso sexualizado da picana e outros aspectos sexuais presentes na tortura praticada na Argentina, cf. GRAZIANO, Francisco. Divine Violence: Spectacle, Psychosexuality, and Radical Christianity in the Argentine 'Dirty War'. Boulder; Oxford: Westviews, 1992. especialmente p. 153-158.

${ }^{16} \mathrm{O}$ estupro de mulheres durante a tortura foi bem documentado, mas casos relatados do estupro de homens são menos frequentes. É difícil determinar a frequência com que prisioneiros do sexo masculino foram sujeitados a alguma forma de estupro. Está claro, entretanto, que o estupro às vezes foi usado para torturar homens bem como mulheres. O Dr. Liwsky, cujo extenso testemunho abre o relatório Nunca más, descreve detalhadamente o tratamento a que foi submetido: "Otro día me llevaron y, a pesar del tamaño de los testículos, me acostaron una vez más boca abajo. Me ataron y, sin apuro, desgarrando conscientemente, me violaron introduciendome en el ano un objeto metálico. Después me aplicaron electricidad por medio de ese objeto, introducido como estaba. No sé describir la sensación de cómo se me quemaba todo por dentro" (versão em espanhol extraída de < http://www.desaparecidos.org/nuncamas/web/investig/articulo/ nuncamas/nmas1c01.htm>). 
incomum ou excepcional. Em segundo lugar, a consciência da humilhação sexual de uma vítima entre o público mais amplo era, muitas vezes, uma parte importante dessa humilhação.

Diante desse pano de fundo, a crucificação de Jesus pode ser vista levando em conta uma pergunta perturbadora: até que ponto a tortura e crucificação de Jesus envolveram alguma forma de abuso sexual? Os testemunhos da América Latina do século XX criam suspeitas hermenêuticas que merecem um exame cuidadoso dos evangelhos para ver se há qualquer indício ou prova de que esse foi o caso.

Para explorar melhor essa questão, é útil distinguir entre abuso sexual que envolve apenas humilhação sexual (como nudez forçada, deboche sexual e insultos sexuais) e abuso sexual que inclui agressão sexual (que envolve contato sexual forçado e se estende desde molestamento até penetração, ferimento ou mutilação). Sustentarei que os evangelhos indicam claramente que a humilhação sexual foi um traço proeminente no tratamento de Jesus e que a humilhação sexual foi um aspecto importante da crucificação. Se esse é o caso, a possibilidade de agressões sexuais contra Jesus também precisará ser considerada. Na ausência de indícios ou provas claras para decidir isso de uma maneira ou de outra, sugerirei que o que se mostrou tão comum em práticas recentes de tortura não pode ser inteiramente excluído no tratamento dispensado a Jesus.

A crucificação no mundo da Antiguidade parece ter sido portadora de um elemento fortemente sexual e deveria ser entendida como uma forma de abuso sexual que envolvia humilhação sexual e, em alguns casos, agressão sexual. Ela pretendia ser mais do que a terminação da vida; antes da morte efetiva, procurava reduzir a vítima a algo menos do que humana aos olhos da sociedade. As vítimas eram crucificadas nuas, no que equivalia a uma forma ritualizada de humilhação sexual pública. Em uma sociedade patriarcal, em que os homens competiam entre si para exibir virilidade em termos de poder sexual sobre outros, a exibição pública da vítima nua pelos "vitoriosos" na frente de espectadores e passantes levava a mensagem de dominação sexual. A cruz apresentava a vítima para exibição como alguém que tinha sido - ao menos metaforicamente - emasculado. ${ }^{17}$ Dependendo da posição em que a vítima era crucificada, a exibição dos órgãos genitais podia ser especialmente enfatizada. Tanto Josefo como o historiador romano Sêneca, o Jovem atestam o entusiasmo dos romanos com a experimentação de posições de crucificação diferentes. ${ }^{18}$ Além disso, a

171 Samuel sugere que a emasculação e agressão sexual também eram práticas reconhecidas em um período anterior da história de Israel. Sobre a emasculação, cf. 1 Samuel 18.27: [...] dispôs-se Davi e partir com seus homens, e feriram dentre os filisteus 200 homens; trouxe seus prepúcios e os entregou todos ao rei, para que lhe fosse genro. Sobre o medo de agressão sexual, cf. 1 Samuel 31.4: Então, disse Saul ao seu escudeiro: Arranca tua espada e atravessa-me com ela, para que, porventura, não venham estes incircuncisos, e me traspassem, e escarneçam de mim. Agradeço a John Jarick por chamar minha atenção para essas passagens.

${ }^{18}$ Quanto a Josefo, cf. War V, 452 (v. supra); Sêneca, Consolação a Márcia, 20.3: "Vejo nos tiranos cruzes de mais de uma espécie, variadas em sua fantasia: um suspende suas vítimas de cabeça para baixo; o outro atravessa o corpo com uma estaca que vai do tronco à boca, outro lhes estende os braços a uma forca [...]" (versão em português extraída de <http://www.scielo.br/pdf/rlpf/v10n1/1415-4714-rlpf-10-1-0156.pdf >). 
descrição de Sêneca sugere que a violência sexual contra a vítima era, às vezes, levada ao mais brutal extremo, com cruzes que empalavam os órgãos genitais da vítima. Essa prática talvez nunca tenha ocorrido na Palestina - e não há indícios ou provas de que tenha acontecido com Jesus -, mas, ao menos, ela sugere o contexto altamente sexualizado de violência em que as crucificações romanas às vezes ocorriam.

O elemento sexual das práticas romanas fazia parte de sua mensagem de terror. Qualquer pessoa que se opusesse aos romanos não só perderia sua vida, mas também seria despojada de toda honra pessoal e dignidade humana. Por isso não é surpreendente que os próprios evangelhos indiquem que havia um nível elevado de humilhação sexual na forma como Jesus foi açoitado, insultado e então crucificado. A partir de indícios do mundo da Antiguidade, parece que açoitar a vítima em público enquanto ela estava nua era rotina. Marcos, Mateus e João sugerem, todos, que esse também foi o caso do açoitamento de Jesus. ${ }^{19}$ De igual maneira, como se observou acima, a crucificação geralmente ocorria enquanto a vítima estava nua, e há poucas razões para crer que Jesus ou outros judeus tivessem sido uma exceção a isso. ${ }^{20}$ Se a finalidade fosse humilhar a vítima, a nudez completa teria sido particularmente vergonhosa no contexto judaico. ${ }^{21}$ Além disso, antes da crucificação Jesus foi entregue a uma coorte de

19 Embora Marcos 15.15; Mateus 27.26 e João 19.1 não sejam explícitos nesse tocante (e Lucas não mencione um açoitamento), a sequência de acontecimentos descritos por eles sugere isso fortemente. Marcos e Mateus (que situam o açoitamento no final do julgamento) e João (que o situa no meio) relatam que imediatamente após o açoitamento Jesus foi entregue aos soldados romanos para ser escarnecido. Todos os três apresentam o primeiro ato de zombaria como o fato de os soldados terem vestido Jesus de púrpura e com uma coroa de espinhos (Mc 15.17), manto de púrpura (Jo 19.2) ou manto escarlate (Mt 27.28). Não há menção da necessidade de despi-lo antes de fazer isso. Em contraposição a isso, tanto Marcos 15.20 como Mateus 27.31 mencionam explicitamente que, após o escarnecimento, despiram-lhe a púrpura ou o manto e recolocaram suas roupas nele para a procissão até Gólgota. Brown observa que o costume usual fora da Palestina era que o condenado desfilasse nu para a execução, mas as exceções a essa prática na Palestina podem ter sido uma concessão aos escrúpulos judeus quanto à nudez em público (cf. BROWN, 1994, p. 870). É possível que essa sensibilidade fosse especialmente alta dentro dos limites da cidade santa.

${ }^{20}$ Isso fica mais claro em João 19.23-24, que relata que, depois de colocar Jesus sobre a cruz, os soldados tomaram suas vestes para dividi-las entre si, e elas incluíam sua túnica, sobre a qual lançaram sortes para não rasgá-la. Os evangelhos sinóticos (Mc 15.24; Mt 27.35 e Lc 23.34) são um pouco mais vagos e simplesmente fazem referência à divisão de suas roupas por sorteio. Em uma avaliação cuidadosa dos indícios, Raymond Brown apoia cautelosamente a probabilidade de nudez completa. Embora Brown relate que os evangelistas não são específicos quanto à questão e poderiam não ter certeza quanto a ela, ele propõe três razões que apoiariam a opinião de que Jesus estava completamente nu (BROWN, 1994, p. 952-953).

21 Sobre a humilhação deliberada de inimigos por meio da exposição dos órgãos genitais, cf. 2 Samuel 10.45, que descreve como os enviados de Davi foram pegos por Hanum e mandados de volta com sua barba rapada pela metade e suas roupas "cortadas pela metade até as nádegas". A sensibilidade judaica para com exposições insultuosas do corpo também se mostra em um desastre que ocorreu durante a época em que Cunamo era governador (48-52 d.C.). Josefo relata que um soldado de guarda na colunata do templo durante a Festa dos Pães Ázimos levantou sua túnica, curvou-se indecentemente e se expôs às multidões mais abaixo enquanto produzia ruídos indecentes (War II. 223-27). Temendo um tumulto na comoção que se seguiu, Cumano enviou uma infantaria pesada, mas isso desencadeou uma reação de pânico, e Josefo afirma que 30 mil pessoas foram esmagadas ao tentarem escapar. 
soldados romanos para ser mais humilhado (Mc 15.16-20; Mt 27.28-31; Jo 19.1-5). ${ }^{22}$ Todos os evangelhos exceto Lucas relatam que os soldados romanos zombaram de Jesus colocando uma coroa de espinhos em sua cabeça (Mc 15.17; Mt 27.29; Jo 19.2) e o vestindo de púrpura (Mc 15.17; Jo 19.2) ou com um manto escarlate (Mt 27.28). ${ }^{23}$ Os textos também mencionam que os soldados cuspiram em Jesus (Mc 15.19; Mt 27.30), bateram nele com um caniço (Mc 15.19; Mt 27.30) e zombaram dele com insultos verbais (chamando-o de rei: Mc 15.18; Mt 27.29; Jo 19.3) e uma homenagem simbólica (ajoelhando-se diante dele: Mc 15.19; Mt 27.29; Jo 19.2). ${ }^{24}$

Com base no que os próprios textos dos evangelhos indicam, o elemento sexual no abuso é inevitável. Um homem adulto foi despido para o açoitamento, depois vestido de um modo insultuoso para que uma multidão de soldados pudesse zombar dele, bater e cuspir nele antes de ser despido de novo (ao menos em Mc 15.20 e Mt 27.31) e vestido de novo para passar pela cidade - já fraco demais para carregar sua própria cruz - só para ser despido mais uma vez (uma terceira vez) e exibido para morrer nu a uma multidão que escarnecia dele. Quando a apresentação textual é formulada assim, o elemento sexual do abuso fica claro: a afirmação só é controvertida na medida em que parece surpreendente em vista das apresentações usuais. ${ }^{25} \mathrm{O}$ elemento sexual da tortura é minimizado em representações artísticas da crucificação que mostram Jesus usando uma tanga. Essas imagens nos distanciam do texto bíblico, talvez porque o elemento sexual tenha sido perturbador demais para ser enfrentado.

Embora seja vital reconhecer a humilhação sexual revelada no texto, o que os textos talvez ocultem também pode ser significativo. Pode ter havido um nível de abuso sexual no pretório que nenhum dos evangelhos revela imediatamente. Essa suspeita é motivada pelos testemunhos da América Latina apresentados mais acima. Embora os testemunhos da América Latina nada façam para estabelecer os fatos históricos da

22 Para Marcos e Mateus, isso acontece no fim do julgamento e ambos mencionam que teria ocorrido no pretório. Para João, a zombaria ocorre durante o julgamento e parece ter sido realizada dentro do quartel-general de Pilatos (18.28).

${ }^{23}$ Lucas situa o escarnecimento de Jesus bastante cedo no relato, em um ponto em que é improvável que ele tenha envolvido soldados romanos. Segundo Lucas 22.63-64, a zombaria ocorre antes do julgamento perante os anciãos judaicos. A zombaria, o espancamento, a vendagem dos olhos e o desafio para que ele profetizasse (Lucas não menciona cusparadas) foram feitos pelos guardas que ficaram com Jesus durante a noite antes do julgamento diante do Sinédrio. Provavelmente eles eram integrantes da "multidão" que, segundo Lucas 22.47, o capturou. Marcos 15.18-19 e Mateus 26.67-68 também relatam que Jesus foi objeto de cusparadas e pancadas e desafiado a profetizar, mas situam isso imediatamente depois de sua condenação pelo Sinédrio, e não antes, e dizem que isso foi feito por membros do próprio Sinédrio. João não menciona qualquer tratamento paralelo associado ao questionamento por parte do sumo sacerdote (João 18.19-24).

${ }^{24}$ Além disso, Mateus 27.29 também menciona que colocaram um caniço na mão direita de Jesus antes de baterem nele, e, embora João não mencione o caniço, João 19.3 diz que ele foi esbofeteado.

25 Este artigo está preocupado primordialmente com a maneira como os textos apresentam os acontecimentos. A descrição do abuso apresentada por eles é historicamente muito plausível, mas uma avaliação adicional da historicidade textual não será tentada aqui. Levando em conta a vergonha e o constrangimento que devem ter estado associados ao abuso sexual, é provável que os evangelhos o mitiguem, e não que o exagerem. 
crucificação na Palestina, eles são altamente sugestivos do que pode ter acontecido dentro das paredes fechadas do pretório. ${ }^{26}$

Segundo a descrição tanto de Mateus como de Marcos, Jesus foi entregue enfraquecido e nu - já um homem condenado sem qualquer recurso à justiça - a soldados que o levaram para dentro do pretório e reuniram as outras tropas. ${ }^{27}$ Os dois evangelhos afirmam explicitamente que foi toda a coorte (speira) de soldados romanos - mais de 600 homens - que foi reunida para testemunhar e participar da "zombaria". Isso provavelmente incluía um número significativo de auxiliares sírios que poderiam ter visto seus vizinhos judeus com particular hostilidade. ${ }^{28}$ Levando em conta os testemunhos de estupros coletivos dados por vítimas detidas por forças de segurança nos centros clandestinos de tortura da América Latina, esse detalhe de poder militar esmagador e hostil emite um sinal particularmente perturbador.

Muitos dos integrantes da coorte romana devem ter experimentado os temores e as frustrações da vida militar em um país ocupado, o que poderia ter gerado uma desagradável tensão interior de onipotência e impotência. Como representantes da Roma imperial, os soldados coletivamente exerciam um poder quase ilimitado. Por outro lado, cada soldado individualmente estava na base de uma longa cadeia de comando hierárquico romano e também deve ter sentido sua impotência individual cotidianamente. A reação instintiva a essa impotência é, muitas vezes, impor o próprio poder à força às pessoas que são menos poderosas ainda. Os soldados individualmente tinham muito pouca liberdade ou opção pessoal de agir quanto a isso, entretanto, e muitas vezes suas interações com a população local devem ter reforçado seus sentimentos de impotência e frustração. O soldado comum muitas vezes deve ter sofrido sem exercer vingança imediata ao se deparar com falta de cooperação, desrespeito ou hostilidade mal disfarçada. O ressentimento criado por essa situação normalmente deve ter sido controlado pela disciplina militar e pelo medo dos superiores militares que queriam evitar encrencas desnecessárias sempre que possível. Não obstante, a ânsia agressiva

${ }^{26}$ A privacidade do pretório (seja o palácio de Pilatos ou a fortaleza Antônia) significa que os detalhes do que transpirou lá dentro são inevitavelmente circunstanciais e provavelmente não eram conhecidos nem mesmo na época. Além disso, mesmo que se acreditasse que Jesus tivesse sofrido agressão sexual no pretório, a ausência disso nos relatos dos evangelhos dificilmente surpreende. Além da distância dos anos e do desejo de passar por alto sobre um acontecimento vergonhoso, os evangelhos são geralmente vistos como portadores de um notável viés para desculpar os romanos pelo julgamento e morte de Jesus.

27 Apesar das tentativas dos evangelhos de isentar Pilatos de culpa, se de fato ocorreu estupro no pretório, provavelmente isso teria sido feito com a aprovação positiva de Pilatos ou sua indiferença consciente. É bem possível que Pilatos tenha entregue Jesus para ser deliberadamente agredido por seus soldados como parte da sentença de crucificação. Essa ação poderia ter servido para reforçar seu próprio status como senhor triunfante que tinha condições de subjugar sexualmente suas vítimas através das ações de seus subordinados. Richard Trexler observa que um senhor romano poderia ter considerado mais insultuoso fazer com que seus escravos estuprassem o jovem pretendente de sua esposa adúltera do que ele próprio estuprar o jovem (TREXLER, Richard. Sex and Conquest: Gendered Violence, Political Order, and the European Conquest of the Americas. Cambridge: Polity, 1995. p. 22).

28 Josefo sugere que, ao menos enquanto Félix foi procurador (52-60 d.C.), a maioria dos integrantes da guarnição romana em Cesareia eram criados na Síria e estavam dispostos a tomar o lado dos habitantes sírios de Cesareia em uma disputa civil contra seus cidadãos judaicos (War, II 266-270 [268]). 
de vingança deve ter permanecido perto da superfície e poderia ensejar violência extrema quando os superiores estivessem dispostos a fechar um olho ou sancionar sua expressão sobre uma vítima sacrifical. O desejo de botar para fora as frustrações e brutalidades da vida militar por meio de violência sexual ensejou atrocidades ao longo de toda a história.

O relato de Josefo a respeito do cerco de Jerusalém (War, V. 420-572) sugere que as comparações entre o mundo da Antiguidade e as práticas de tortura na América Latina do século XX podem ser apropriadas. A descrição de Josefo de como os militantes judaicos dentro de Jerusalém torturavam a população civil em busca de comida oferece uma percepção gráfica de torturas sexuais da época: "Os métodos de tortura que eles inventaram em sua busca de comida eram terríveis. Enfiavam ervilhaca azeda nas passagens genitais de suas vítimas e estacas pontiagudas em seus traseiros" (War, V. 435). Embora a historicidade efetiva das afirmações de Josefo dificilmente possa ser tida como certa (já que ele estava escrevendo para um público romano e seus exageros e seu interesse manifesto em passar uma imagem ruim dos rebeldes judaicos afetam seu testemunho em todo o seu relato), elas sugerem, não obstante, que as torturas sexualizadas da América Latina do século XX poderiam corresponder bem estreitamente a seus equivalentes mediterrâneos do século I. De igual modo, a descrição feita por Platão em Górgias de uma crucificação hipotética (precedida por tortura e castração enquanto a vítima estava na roda [antigo instrumento de tortura]) indica que poderia ter ocorrido castração antes da crucificação em ao menos algumas partes do mundo da Antiguidade. ${ }^{29}$ Além disso, o historiador Richard Trexler afirmou que o estupro anal de cativos do sexo masculino era "uma prática notoriamente comum no mundo da Antiguidade" ${ }^{" 30}$. Levando em conta esse pano de fundo, é importante perguntar se o beijo de saudação fraternal e respeitoso no jardim do Getsêmani poderia ter desencadeado acontecimentos que levaram a alguma forma de agressão sexual no pretório de Pilatos. ${ }^{31}$

A privacidade do pretório faz com que não seja realista esperar uma resposta definitiva sobre o que exatamente aconteceu lá dentro. Não obstante, as suspeitas levantadas pelas pessoas que sofreram sob recentes regimes latino-americanos sugerem que se coloque um ponto de interrogação contra a completitude das narrativas

${ }^{29}$ Górgias, 473C, apud SLOYAN, 1995, p. 16.

30 TREXLER, 1995, p. 20. De acordo com o autor, "no mundo da Antiguidade grega [...] o sinal principal de dependência masculina era ser anal ou oralmente penetrado por outro homem sem, ao menos ficticiamente, ser capaz de resistir" (p. 33), e "Sêneca [...] afirmou que "maus oficiais do exército e tiranos perversos são as principais fontes de estupros de jovens do sexo masculino"” (p. 34). Nesse contexto, até mesmo a suposição amplamente aceita de que os soldados tenham forçado Jesus a usar roupas escarlates ou de púrpura para zombaria unicamente política poderia ser reconsiderada. Vestir uma vítima do sexo masculino com roupas de cores vivas também poderia ter sido um prelúdio para a agressão sexual (cf. TREXLER, 1995, p. 34).

${ }^{31}$ Isso também poderia ter implicações para a questão da razão por que Judas teve sentimentos profundos de arrependimento por suas ações (Lc 22.3-5). Judas talvez não tenha previsto todas as implicações de sua traição e, se o argumento aqui apresentado está correto, seu desespero e sua vergonha seriam fáceis de entender. 
dos evangelhos nesse ponto. Há uma possibilidade de que a íntegra dos detalhes do sofrimento de Jesus esteja faltando nos relatos dos evangelhos. Ainda que os textos ofereçam indicações claras de humilhação sexual, a possibilidade de agressão sexual só pode se basear no silêncio e na circunstância. Contudo, dever-se-ia lembrar que, embora fazer uma distinção entre humilhação e agressão no abuso sexual seja útil, também pode haver uma sobreposição considerável entre elas e as duas tendem a andar de mãos dadas. Na tortura sexual, a agressão sexual é uma forma de humilhação sexual por excelência, e a humilhação sexual muitas vezes se baseia na ameaça de agressão física ou sexual. Que forma de agressão sexual - se houve alguma - poderia ter efetivamente ocorrido pode ser impossível de definir, mas a possibilidade precisa ser reconhecida e enfrentada mais honestamente do que tem acontecido até agora. Para lançar luz sobre isso, necessita-se obviamente de uma investigação histórica adicional sobre o tratamento de prisioneiros condenados por parte de soldados romanos e o tratamento de Jesus em particular. Para que isso aconteça, porém, é apropriado fazer uma pausa e perguntar a que finalidade positiva essas linhas de pesquisa servirão.

\section{Perspectivas teológicas e pastorais}

Constatei que a direção para a qual minha pesquisa me levou é muito perturbadora e me dou conta de que outras pessoas se sentirão da mesma maneira. Creio, entretanto, que, para as pessoas cristãs na atualidade, essas questões poderiam servir a finalidades construtivas nos campos da teologia e da pastoral. Tanto nossa resistência como nossa abertura a essa linha de investigação poderiam levar a novas percepções e descobertas.

Em primeiro lugar, confrontar-se com a possibilidade de abuso sexual na paixão de Cristo poderia aprofundar a compreensão cristã da solidariedade de Deus com as pessoas sem poder. O abuso sexual é uma afirmação destrutiva de poder, e não simplesmente um resultado de desejo. Ele mostra os impulsos pecaminosos e consequências degradantes que o poder distorcido pode gerar na sociedade humana. Um elemento importante na doutrina cristã é que Jesus enfrentou o poder do mal e sofreu a morte na cruz em decorrência disso. As concepções apresentadas aqui - de que Jesus foi vítima de abuso sexual na humilhação sexual pela qual passou e talvez tenha sido até vítima de agressão sexual - são profundamente penosas. Elas podem, contudo, oferecer percepções para uma compreensão cristã mais plena de um Deus que é realmente solidário com as pessoas sem poder e sofre os piores males do mundo. Um juízo a priori de que Jesus não sofreu nem poderia sofrer abuso sexual pode acompanhar um pressuposto não examinado de que Jesus não foi de fato plenamente humano, que é uma forma da heresia docética, que nega a forma real do sofrimento físico de Jesus. A recusa de aceitar que Jesus poderia ter sofrido abuso sexual sugere uma recusa de aceitar a encarnação plena de Cristo na história humana. Dizer que Jesus não poderia ter sido vulnerável aos piores abusos do poder humano significa negar que ele fosse, afinal, verdadeiramente humano. 
Pastoralmente, confrontar-se com a possibilidade de abuso sexual na paixão de Cristo poderia proporcionar ajuda prática para vítimas contemporâneas de tortura e abuso sexual. O reconhecimento de abuso sexual no tratamento dado a Jesus poderia levar uma mensagem libertadora e curativa para as mulheres, crianças e homens da América Latina e de outros lugares que também sofreram abuso. A aceitação de que até mesmo Jesus pode ter sofrido o mal dessa maneira pode dar uma nova dignidade e respeito próprio às pessoas que continuam a se debater com o estigma e outras consequências do abuso sexual. Um Deus que, por meio de Cristo, deve ser identificado com as pessoas famintas, sedentas, forasteiras, nuas, doentes e prisioneiras (Mt 25.3146) também deve ser identificado com aquelas que sofrem abuso e tortura no mundo contemporâneo. Isso se aplica independente de Jesus ter sido "meramente" humilhado em termos sexuais em público ou também agredido privadamente.

\section{Conclusão}

A despeito da existência de armadilhas em potencial, a dinâmica do terror de Estado na América Latina e em outros países pode ser um ponto de partida frutífero para se obter percepções a respeito dos evangelhos. Uma consciência dos abusos de direitos humanos na América Latina pode produzir percepções importantes acerca do contexto político e de todo o horror da crucificação de Jesus. O papel das crucificações na produção e manutenção do terror de Estado e o elemento de abuso sexual nas práticas romanas exigem uma investigação adicional. Os evangelhos indicam que houve um nível elevado de humilhação sexual pública no tratamento dispensado a Jesus, e as paredes fechadas do pretório apresentam uma pergunta perturbadora sobre o que mais poderia ter acontecido lá dentro.

\section{Referências}

ARCHDIOCESE OF SÃO PAULO. Torture in Brazil: A Report by the Archdiocese of São Paulo. New York: Vintage, 1986.

BOFF, Clodovis. Teologia e prática: teologia do político e suas mediações. Petrópolis: Vozes, 1978.

BROWN, Raymond E. Death of the Messiah. New York: Doubleday, 1994.

CORRADI, Juan E. et al. (ed.). Fear at the Edge: State Terror and Resistance in Latin America. Berkeley; Los Angeles, CA: University of California Press, 1992.

FIGUEROAALVEAR, Rocío; TOMBS, David. Recognising Jesus as a Victim of Sexual Abuse: Responses from Sodalicio Survivors in Peru. Dunedin: Centre for Theology and Public Issues, University of Otago, 2019. Disponível em: <http://hdl.handle.net/10523/8976> [em inglês]. Reconociendo a Jesús como víctima de abuso sexual: respuestas de sobrevivientes del Sodalicio en el Perú. Dunedin: Centro de Teología y Asuntos Públicos, Universidad de Otago, 2019. Disponível em: <http://hdl.handle.net/10523/9222> [em espanhol].

GRAZIANO, Francisco. Divine Violence: Spectacle, Psychosexuality, and Radical Christianity in the Argentine 'Dirty War'. Boulder; Oxford: Westview, 1992.

HENGEL, Martin. Crucifixion in the Ancient World and the Folly of the Cross. Philadelphia: Fortress; London: SCM, 1977 [original em alemão: 1976]. 
JOSEPHUS. The Jewish War. [1959]. Trad. G. A. Williamson. Ed. rev. Harmondsworth: Penguin, 1970.

MOORE, Stephen D. God's Gym: Divine Male Bodies of the Bible. New York: Routledge, 1996. NATIONAL COMMISSION ON DISAPPEARED PEOPLE. Nunca Más: A Report by Argentina's National Commission on Disappeared People. Boston; London: Faber and Faber, 1986.

NATIONAL COMMISSION ON TRUTH AND RECONCILIATION. Report of the Chilean National Commission on Truth and Reconciliation. Notre Dame, IN: Centre for Civil and Human Rights, Notre Dame Law School, 1993.

SCARRY, Elaine. The Body in Pain: The Making and Unmaking of the World. Oxford: Oxford University Press, 1987.

SLOYAN, Gerard S. The Crucifixion of Jesus: History, Myth, Faith. Minneapolis: Fortress, 1995. TOMBS, David. Crucifixion, State Terror, and Sexual Abuse. Union Seminary Quarterly Review, v. 53, p. 89-109, 1999. Disponível em: <http://hdl.handle.net/10523/6067>.

TOMBS, David. Prisoner Abuse: From Abu Ghraib to the Passion of the Christ. In: HOGAN, Linda; LEHRKE Dylan (ed.). Religions and the Politics of Peace and Conflict. Princeton, NJ: Princeton Theological Monograph Series, 2009. p. 179-205.

TOMBS, David. Crucifixion, State Terror, and Sexual Abuse: Text and Context. Dunedin: Centre for Theology and Public Issues, University of Otago. Disponível em: $<$ http://hdl.handle. net/10523/8558> [em inglês]. Crucifixión, terrorismo de Estado y abuso sexual: Texto y contexto. Dunedin: Centro de Teología y Asuntos Públicos, Universidad de Otago, 2018. Disponível em: $<$ http://hdl.handle.net/10523/8988> [em espanhol].

TREXLER, Richard. Sex and Conquest: Gendered Violence, Political Order, and the European Conquest of the Americas. Cambridge: Polity, 1995.

TRUTH COMMISSION FOR EL SALVADOR. From Madness to Hope: The 12-Year War in El Salvador. New York: United Nations, 1993. 